\title{
Appraisal of groundwater pollution on account of nitrate and lead concentrations in Yamuna-Sahibi interfluve in Delhi, India

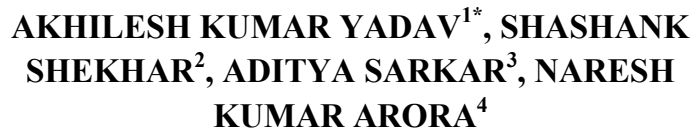

\begin{abstract}
The presence of certain pollutants such as nitrate $\left(\mathrm{NO}_{3}\right)$ and lead $(\mathrm{Pb})$ in groundwater is often associated with encroachment of urbanization in a natural system. This phenomenon has been observed in many metropolitan cities such as Delhi in India. However, in recent times, the extent of these pollutants has also been observed beyond urban settings. Thus, this study tries to understand the associations of nitrate and lead pollution in groundwater with factors other than urbanization in of Delhi, mainly focussing on areas located with the Yamuna-Sahibi interfluve. The initial observations revealed that $97 \%$ samples from the study area showed nitrate concentrations beyond the permissible limit set by WHO (100 ppm). Similarly, lead pollution was also observed to be widespread as per the WHO standard (10 ppb). Most of the studies have attributed unplanned sewerage as the primary source of pollution. However, in light of the fact that Delhi is known to have a complex hydrogeological setting, we propose a detailed insight into the trends and variation in distribution of these pollutant to understand the geochemical processes involved.
\end{abstract}

Key words: Delhi, Groundwater Pollution, Nitrate, Lead. 